\title{
Joint FAO/IAEA coordinated research project on "comparing rearing efficiency and competitiveness of sterile male strains produced by genetic, transgenic or symbiont-based technologies"
}

\author{
Kostas Bourtzis $^{1 *}$, Carlos Cáceres ${ }^{1}$ and Marc F. Schetelig ${ }^{2}$
}

Keywords: Sterile insect technique, Insect pests, Insect disease vectors, Genetic sexing strains

Insects represent the most abundant and speciose group of animals on earth, with recent studies estimating the total number of species between 3 and $30 \times 10^{6}[1,2]$. However, a small number of them represent pests for agriculture and livestock or vector major pathogens to humans and animals [3]. Area-wide integrated pest management (AW-IPM) programs with a sterile insect technique component (SIT) have been used to control populations for insect pests and disease vectors worldwide [4]. The SIT is based on the mass rearing and sterilization of insects by ionizing radiation and their subsequent handling, transport, and repeated releases, at appropriate overflooding ratios and in an area-wide manner, to suppress or locally eradicate a target population $[3,5]$. Although SIT has been successfully applied by releasing both sterile males and sterile females, several studies have shown that sterile male-only releases can significantly improve the efficacy, cost-effectiveness and, in the case of mosquito SIT, also the biosecurity of SIT applications [6-8]. Male-only production can be efficiently and robustly achieved by developing specific sexing mechanisms that allow the separation of males and females in early stage prior to the release of sterile insects. The most

\footnotetext{
* Correspondence: K.Bourtzis@iaea.org

'Insect Pest Control Laboratory, Joint FAO/IAEA Programme of Nuclear Techniques in Food and Agriculture, Vienna, Austria

Full list of author information is available at the end of the article
}

successful example of genetic sexing strains (GSS), the VIENNA 7 and VIENNA 8 strains of the Mediterranean fruit fly, Ceratitis capitata, are in use worldwide for the implementation of SIT programs to control this pest $[9,10]$.

Sterile males can be produced by combining classical genetics and ionizing radiation, but they can also be produced by transgenic or symbiont-based approaches. The coordinated research project (CRP) entitled "Comparing rearing efficiency and competitiveness of sterile male strains produced by genetic, transgenic or symbiont-based technologies" of the Insect Pest Control Subprogramme of the Joint Division of Nuclear Techniques in Food and Agriculture of the Food and Agriculture Organization (FAO) and the International Atomic Energy Agency (IAEA) aimed: (a) to develop novel GSS or the refinement of existing ones, which may have produced by different technological platforms; (b) to perform quality control analysis of different strains mainly in respect to their rearing efficiency and mating competitiveness and (c) to assess the genetic stability of the strains by different technological platforms. This 5-year project (2015-2019) was coordinated by Kostas Bourtzis, a member of the Insect Pest Control Subprogramme of the FAO/IAEA, and included 18 scientists from 14 countries. This special issue presents the results and achievements of the research work carried out in the frame of this project.

Meza and colleagues report the development and characterization of the first GSS of the South American 
fruit fly Anastrepha fraterculus sp. 1 [11]. The GSS was constructed by combining classical genetics and irradiation approaches and using the black pupae $(b p)$ gene as a selectable marker. In the new strain, males emerge from brown pupae and females from black pupae. This GSS sets the ground for the development and implementation of SIT applications against this major agricultural pest in South America. Aketarawong and colleagues evaluated the Salaya 1 GSS of the Oriental fruit fly Bactrocera dorsalis based on the white pupae ( $w p$ ) gene selectable marker, under semi-mass rearing conditions [12]. The results clearly showed that the genetic stability, genetic diversity, and the overall biological quality of this GSS, which was also developed by the combination of classical genetics and irradiation approaches, is maintained during the production in the mass rearing facility by using protocols to rearing GSS strains included the set-up of the filter rearing system that ensures the integrity of the sexing characteristics of the strain.

The Queensland fruit fly, Bactrocera tryoni, represents a major agricultural pest for Australia. There are ongoing efforts to develop and implement a large-scale operational SIT project for its population control. During this CRP, Choo and colleagues used CRISPR/Cas9-based approaches to introduce single point mutations in the shibire gene to use it as a conditional selectable marker for the development of GSS for this pest species [13]. Popa-Baez and colleagues applied the "common garden" approach in B. tryoni to investigate naturally occurring genetic variation in traits such as heat, desiccation, and starvation resistance and to assess the impact of domestication on them [14]. Their results clearly show that variation exists, and it is possible to identify populations with key traits for SIT applications, such as high heat, desiccation, and starvation resistance. However, the variation declines very fast during domestication, indicating the need for careful selection plans to minimize the loss of useful traits. Yeap and colleagues studied two defining characters, mating time and callus color, in the sibling species Bactrocera tryoni and Bactrocera neohumeralis using hybrid recombinant analysis [15]. Their results indicated that the two traits, although tightly linked, can be separated, and each respective phenotype is determined by more than one gene. From an applied point of view (domestication, mass rearing, and SIT applications), it is important to note that the Bactrocera tryoni phenotypes are selected under laboratory conditions. Further on, research efforts were also focused on another Bactrocera species, the olive fruit fly Bactrocera oleae. Tsoumani and colleagues report on the identification and characterization of the odorant receptor co-receptor (orco) gene, which encodes for the Orco [16]. This olfactory co-receptor plays a crucial role in the mating behavior of the olive fruit fly, at both pre- and post-mating level, and represents a target for the development of novel control strategies in support of SIT. Carraretto and colleagues report on the discovery of repetitive sequences on the $\mathrm{Y}$ chromosome of Bactrocera dorsalis which may set the ground for a useful marking system and molecular karyotyping in this species [17].

The spotted wing Drosophila, Drosophila suzukii, is an invasive species and a major agricultural pest, and has been the target of development for novel genetic control strategies. In the present special issue, Yan and colleagues present the isolation and characterization of four cellularization genes nullo, serendipity- $\alpha$, bottleneck, and slow-asmolasses including their promoters [18]. Given that these genes are active during embryogenesis, their promoters can be used to express factors for the induction of sterility or for sexing in support of SIT applications against this pest species. In addition, Ahmed and colleagues showed that higher piggyBac germline transformation efficiency can be achieved by using the D. suzukii Alps line compared to others [19]. In the same study, the authors also constructed several $\phi C 31-\mathrm{RMCE}$, early embryo-specific, and spermatogenesis-specific driver lines, which can be proven useful for future genetic engineering efforts for the population control of this pest.

Novel tools were also developed for other insect species. Primo and colleagues performed Cas9-sgRNA injections into Ceratitis capitata XX-only embryos targeting the autosomal transformer (tra) gene [20]. This resulted in the production of XX males as expected. However, the authors noted that some of the XX males did not have any mutations in the tra gene clearly indicating that the Cas9-sgRNA injections or the injection of inactive Cas9 can lead to masculinization without the induction of mutations. Handler and Schetelig used the transposable hopper element isolated from Bactrocera dorsalis to successfully transform Drosophila melanogaster and the SIT target pest species the Caribbean fruit fly, Anastrepha suspensa [21]. Scannapieco and colleagues report on the transcriptomic analysis of embryos, males, and females of Anastrepha fraterculus sp. 1, thus providing useful information for the development, courtship, and reproduction of this species [22]. This study together with the one by Giardini and colleagues, which reports on the cytogenetic analysis with an emphasis on sex chromosomes polymorphism, provides useful tools for the development of genetic control methods against the South American fruit fly Anastrepha fraterculus sp. 1 [23].

In the frame of the CRP, research studies on fruit fly symbionts were also carried out. Cai and colleagues present a comparative genomic analysis of the gutassociated symbiont of Bactrocera dorsalis, a member of the Klebsiella genus, which sheds light on host-symbiont interactions and the role this symbiotic bacterium may play in the biology and physiology of the Oriental fruit fly [24]. Nikolouli and colleagues studied the gut-associated 
bacterial species and the genetic profile of natural $C$. capitata populations originating from Europe, Africa, Australia, and the Americas [25]. The results showed clear genetic differentiation while reduced diversity was detected in the associated microbiota indicating the important role of geographic expansion and colonization pathways.

Significant progress was achieved during this CRP with respect to the development of male-only strains for two major livestock pests: Lucilia cuprina, a major pest of sheep, and Cochliomyia hominivorax, a major pest of warm-blooded animals. The first study by Yan and Scott reports on the construction and characterization of a Tet-off based transgenic sexing strain of Lucilia cuprina, which exhibits enhanced stability and reduced risk for resistance because the authors combined two lethal effectors in a single strain [26], Concha and colleagues present the construction and characterization of several transgenic sexing strains for the New World screwworm, Cochliomyia hominivorax, using an early female lethal system, which could potentially enhance the SIT applications against this major pest [27].

An interesting recent expansion has been the development of genetic sexing strains for a major mosquito vector species, Aedes aegypti, using classical genetic approaches [28]. A key parameter in GSS is genetic stability, which can be affected by recombination events. In this issue, Augustinos and colleagues used ionizing radiation to induce chromosomal inversions, known as suppressors of genetic recombination [29]. One of them (Inv35) was subsequently used for the construction of a red-eye GSS in Aedes aegypti, which can be used in SIT applications for the population suppression of this vector to fight against major pathogens such as dengue, chikungunya, Zika, and yellow fever.

As guest editors, we believe that this issue of BMC Genetics presents significant information on how GSS can be developed, refined, and evaluated for their biological quality and potential use in large-scale operational population control programs against insect species and disease vectors. In addition, recent discoveries of the Malenesson-the- $Y(\mathrm{MoY})$ gene, the male determining factor in Tephritids, and the white pupae $(w p)$ gene, which has been used as a selectable marker in several tephritid GSS, set the ground for the development of generic approaches for the construction of GSS against insect pests and disease vectors [30, 31]. This will be the focus of a new 5year long (2019-2024) Coordinated Research Project on "Generic approach for the development of genetic sexing strains for SIT applications".

\section{Abbreviations}

AW-IPM: Area-wide integrated pest management; CRP: Coordinated research project; FAO: Food and Agriculture Organization of the United Nations; GSS: Genetic sexing strains; IAEA: International Atomic Energy Agency; SIT: Sterile insect technique component

\section{Acknowledgements}

This study has benefitted from discussions at the International Atomic Energy Agency funded meetings for the Coordinated Research Project 'Comparing Rearing Efficiency and Competitiveness of Sterile Male Strains Produced by Genetic, Transgenic or Symbiont-based Technologies'.

\section{About this supplement}

This article has been published as part of BMC Genetics Volume 21 Supplement 2, 2020: Comparing rearing efficiency and competitiveness of sterile male strains produced by genetic, transgenic or symbiont-based technologies.

The full contents of the supplement are available online at https://bmcgenet biomedcentral.com/articles/supplements/volume-21-supplement-2.

\section{Authors' contributions}

K.B., C.C. and M.F.S. wrote the manuscript. All authors read and approved the final manuscript.

\section{Funding}

Publication costs are funded by the Joint FAO/IAEA Division of Nuclear Techniques in Food and Agriculture, IAEA (CRP No.: D4.20.16) Vienna, Austria. The funding body played no role in the design of the study and collection, analysis, and interpretation of data and in writing the manuscript.

\section{Competing interests}

The authors declare that they have no competing interests.

\section{Author details}

${ }^{1}$ Insect Pest Control Laboratory, Joint FAO/IAEA Programme of Nuclear

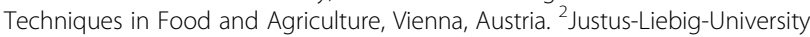
Giessen, Institute for Insect Biotechnology, Insect Biotechnology in Plant Protection, Winchesterstr. 2, 35394 Giessen, Germany.

Published: 18 December 2020

\section{References}

1. Erwin TL. Biodiversity at its utmost: Tropical Forest Beetles. In: Reaka-Kudla ML, Wilson DE, Wilson EO, editors. Biodiversity II. Washington DC: Joseph Henry Press; 1997. p. 27-40.

2. Novotny $V$, Basset $Y$, Miller SE, Weiblen GD, Bremer B, Cizek L, Drozd $\mathrm{PL}$. Host specificity of herbivorous insects in a tropical forest. Nature. 2002;416:841-4

3. Dyck VA, Hendrichs J, Robinson AS, editors. Sterile Insect Technique: principles and practices in area-wide integrated pest management. Dordrecht: Springer; 2005. p. 787

4. Vreysen MJB, Robinson AS, Hendrichs J. Area-wide control of insect pests: from research to field implementation. Dordrecht: Springer; 2007. p. 808.

5. Suckling DM, Kean JM, Stringer LD, Cáceres-Barrios C, Hendrichs J, ReyesFlores J, Dominiak BC. Eradication of tephritid fruit fly pest populations: outcomes and prospects. Pest Manag Sci. 2014;72:456-65.

6. McInnis D, Tam S, Grace C, Miyashita D. Population suppression and sterility rates induced by variable sex ratio, sterile insect releases of Ceratitis capitata (Diptera: Tephritidae) in Hawaii. Ann Entomol Soc Am. 1994;87:231-40.

7. Rendón P, Mclnnis D, Lance D, Stewart J. Medfly (Diptera: Tephritidae) genetic sexing: large-scale field comparison of males-only and bisexual sterile fly releases in Guatemala. J Econ Entomol. 2004;97:1547-53.

8. Papathanos PA, Bourtzis K, Tripet F, Bossin H, Virginio JF, Capurro ML, Pedrosa MC, Guindo A, Sylla L, Coulibaly MB, Yao FA, Epopa PS, Diabate A. A perspective on the need and current status of efficient sex separation methods for mosquito genetic control. Parasit Vectors. 2018;11(Suppl 2):654.

9. Franz G. Genetic sexing strains in Mediterranean fruit fly, an example for other species amenable to large-scale rearing as required for the sterile insect technique. In: Dyck VA, Hendrichs J, Robinson AS, editors. Sterile Insect Technique. Principles and Practice in Area-Wide Integrated Pest Management. Dordrecht: Springer; 2005. p. 427-51.

10. Augustinos AA, Targovska A, Cancio-Martinez E, Schorn E, Franz G, Caceres C, Zacharopoulou A, Bourtzis K. Ceratitis capitata genetic sexing strains: laboratory evaluation of strains from mass rearing facilities worldwide. Entomol Exp Appl. 2017;164:305-17.

11. Meza JS, Bourtzis K, Zacharopoulou A, Gariou-Papalexiou A, Cáceres C. Development and characterization of a pupal-colour based genetic 
sexing strain of Anastrepha fraterculus sp. 1 (Diptera: Tephritidae). BMC Genet. https://doi.org/10.1186/s12863-020-00932-5.

12. Aketarawong N, Isasawin S, Laohakieat K, Thanaphum S. Genetic stability, genetic variation, and fitness performance of the genetic sexing Salaya1 strain for Bactrocera dorsalis, under long-term mass rearing conditions. BMC Genet. https://doi.org/10.1186/s12863-020-00933-4.

13. Choo A, Fung E, Chen IY, Saint R, Crisp P, Baxter SW. Precise single base substitution in the shibire gene by CRISPR/Cas9-mediated homology directed repair in Bactrocera tryoni. BMC Genet. https://doi.org/10.1186/ s12863-020-00934-3.

14. Popa-Baez A, Lee SF, Yeap HL, Prasad SS, Schiffer M, Mourant RG, CastroVargas C, Edwards OR, Taylor PW, Oakeshott JG. Climate stress resistance in male Queensland fruit fly varies among populations of diverse geographic origins and changes during domestication. BMC Genet. https://doi.org/10. 1186/s12863-020-00935-2.

15. Yeap HL, Lee SF, Robinson F, Mourant RG, Sved JA, Frommer M, Papanicolaou A, Edwards OR, Oakeshott JG. Separating two tightly linked species-defining phenotypes in Bactrocera with hybrid recombinant analysis. BMC Genet. https://doi.org/10.1186/s12863-020-00936-1.

16. Tsoumani TK, Belavilas-Trovas A, Gregoriou ME, Mathiopoulos KD. Anosmic flies: what Orco silencing does to olive fruit flies. BMC Genet. https://doi. org/10.1186/s12863-020-00937-0

17. Carraretto D, Aketarawong N, Di Cosimo A, Manni M, Scolari F, Valerio F, Malacrida AR, Gomulski LM, Gasperi G. Transcribed sex-specific markers on the $Y$ chromosome of the Oriental fruit fly, Bactrocera dorsalis. BMC Genet. https://doi.org/10.1186/s12863-020-00938-z.

18. Yan Y, Jaffri SA, Schwirz J, Stein C, Schetelig MF. Identification and characterization of four Drosophila suzukii cellularization genes and their promoters. BMC Genet. https://doi.org/10.1186/s12863-020-00939-y.

19. Ahmed HMM, Heese F, Wimmer EA. Improvement on the genetic engineering of an invasive agricultural pest insect, the cherry vinegar fly, Drosophila suzukii. BMC Genet. https://doi.org/10.1186/s12863-020-00940-5.

20. Primo P, Meccariello A, Inghilterra MG, Gravina A, Del Corsano G, Volpe G, Sollazzo G, Aceto S, Robinson MD, Salvemini M, Saccone G, et al. BMC Genet. https://doi.org/10.1186/s12863-020-00941-4.

21. Handler AM, Schetelig MF. The hAT-family transposable element, hopper, from Bactrocera dorsalis is a functional vector for insect germline transformation. BMC Genet. https://doi.org/10.1186/s12863-020-00942-3.

22. Scannapieco AC, Conte CA, Rivarola M, Wulff JP, Muntaabski I, Ribone A, Milla F, Cladera JL, Lanzavecchia SB. Transcriptome analysis of Anastrepha fraterculus sp. 1 males, females, and embryos: Insights into development, courtship, and reproduction. BMC Genet. https://doi.org/10.1186/s12863020-00943-2.

23. Giardini MC, Nieves M, Scannapieco AC, Conte A, Milla FH, Schapovaloff ME, Frissolo MS, Remis MI, Cladera JL, Lanzavecchia SB. Geographic distribution of sex chromosome polymorphism in Anastrepha fraterculus sp. 1 from Argentina. BMC Genet. https://doi.org/10.1186/s12863-020-00944-1.

24. Cai Z, Guo Q, Yao Z, Zheng W, Xie J, Bai S, Zhang H. Comparative genomics of Klebsiella michiganensis BD177 and related members of Klebsiella sp. reveal the symbiotic relationship with Bactrocera dorsalis. BMC Genet. https://doi.org/10.1186/s12863-020-00945-0.

25. Nikolouli K, Augustinos AA, Stathopoulou P, Asimakis E, Mintzas A, Bourtzis K, Tsiamis G. Genetic structure and symbiotic profile of worldwide natural populations of the Mediterranean fruit fly, Ceratitis capitata. BMC Genet. https://doi.org/10.1186/s12863-020-00946-z.

26. Yan Y, Scott MJ. Building a transgenic sexing strain for genetic control of the Australian sheep blow fly Lucilia cuprina using two lethal effectors. BMC Genet. https://doi.org/10.1186/s12863-020-00947-y.

27. Concha C, Yan Y, Arp A, Quilarque E, Sagel A, Pérez de León A, McMillan OW, Skoda S, Scott MJ. An early female lethal system of the New World screwworm, Cochliomyia hominivorax, for biotechnology-enhanced SIT. BMC Genet. https://doi.org/10.1186/s12863-020-00948-x.

28. Koskinioti P, Augustinos AA, Carvalho DO, Misbah-ul-Haq M, Pillwax G, Duran de la Fuente L, Salvador-Herranz G, Argilés-Herrero R, Bourtzis K. Genetic sexing strains for the population suppression of the mosquito vector Aedes aegypti. Philos Trans B. 2020. https://doi.org/10.1098/rstb. 2019.0808.

29. Augustinos AA, Misbah-ul-Haq M, Carvalho DO, Duran de la Fuente L, Koskinioti P, Bourtzis K. Irradiation induced inversions suppress recombination among between the $\mathrm{M}$ locus and morphological markers in Aedes aegypti. BMC Genet. https://doi.org/10.1186/s12863-020-00949-w.
30. Meccariello A, Salvemini M, Primo P, Hall B, Koskinioti P, Dalíková M, Gravina A, Gucciardino MA, Forlenza F, Gregoriou ME, Ippolito D, Monti SM, Petrella V, Perrotta MM, Schmeing S, Ruggiero A, Scolari F, Giordano E, Tsoumani KT, Marec F, Windbichler N, Nagaraju J, Arunkumar KP, Bourtzis K, Mathiopoulos KD, Ragoussis I, Vitagliano L, Tu Z, Papathanos PA, Robinson MD, Saccone G. Maleness-on-the-Y (MoY) orchestrates male sex determination in major agricultural fruit fly pests. Science. 2019;365:1457-60.

31. Ward CM, Aumann RA, Whitehead M, Nikolouli K, Leveque G, Gouvi G, Fung E, Reiling SJ, Djambazian H, Hughes M, Whiteford S, Caceres-Barrios C, Nguyen T, Choo A, Crisp P, Sim S, Geib S, Marec F, Häcker I, Ragoussis J, Darby AC, Bourtzis K, Baxter SW, Schetelig MF. A generic white pupae sex selection phenotype for insect pest control. bioRxiv. https://doi.org/10.1101/ 2020.05.08.076158

\section{Publisher's Note}

Springer Nature remains neutral with regard to jurisdictional claims in published maps and institutional affiliations.

\section{Ready to submit your research? Choose BMC and benefit from:}

- fast, convenient online submission

- thorough peer review by experienced researchers in your field

- rapid publication on acceptance

- support for research data, including large and complex data types

- gold Open Access which fosters wider collaboration and increased citations

- maximum visibility for your research: over $100 \mathrm{M}$ website views per year

At BMC, research is always in progress.

Learn more biomedcentral.com/submissions 